\title{
PRACTICES AND MORPHOGENESIS
}

\section{Alistair Mutch}

\begin{abstract}
Working within an Archerian morphogenetic framework, I suggest that we to need pay more attention to practices. Instead of the mainstream focus on practice as action, I argue that we should pay attention to practices as a key structural and cultural element of analysis. To illustrate my argument, I draw on historical work on comparative religious practices, specifically the distinction between rituals and routines. A focus on the latter as the conditions of possibility for the former leads to some implications for the thesis of the morphogenesis of contemporary society. An analysis of the relationship between religious rituals and routines stresses the importance of placing both in their wider cultural and structural context. Such an examination points to the significance of advances in technology and changes in modes of dissemination as important factors.
\end{abstract}

KEYWORDS: Practice; religious practice; Church of Scotland; morphogenesis

There has been much discussion in sociological approaches founded on critical realism about the role of practice. In particular, there has been extensive debate about the nature of habitual action (for example, Archer 2010; Porpora 2015; Sayer 2010). The purpose of this article is not to enter into that debate, but to suggest that our focus on habitual action may have diverted our attention from the nature of 'practices' as nouns rather than verbs. By that, I mean that attention to certain forms of practices can be of considerable value in furthering our analysis of contemporary society, directing our attention to new phenomena and providing a 'way in' to the nexus between structure, culture and agency. Specifically, I want to discuss two particular types of practice, namely rituals and routines, both of which are informed by historical investigations of religious organizations and by contemporary debates in organizational analysis.

My analysis is broadly based on the morphogenetic framework of analysis developed by Margaret Archer (Archer 1995). ${ }^{1}$ Like Archer, I have doubts about the value of Bourdieu's concept of 'habitus' in the context of organizational life (Mutch 2003). For Bourdieu, practice is constituted by the 'rules of the game'. It is embedded in the habitus, which it regulates and directs conduct in a largely unconscious fashion. Bourdieu's habitus is an embodied disposition that acts in a similar fashion in different contexts. It is linked the structural conditioning experienced by the actor from birth and is relatively resistant to change. Archer argues that Bourdieu's habitus collapses terms together which need to be held apart for analytical purchase; it therefore provides an impoverished view of the reflective capacity of persons.

These debates are important, but our focus on them has perhaps meant that we have neglected other insights. I note, as does Douglas Porpora (2015) that, according to Archer, there are two senses in which practical action plays a central role in the world. In one sense, pre-linguistic understandings of the world (practical action) give rise to both a sense of the self and to the formation of abstract reasoning. In another sense, embodied persons must necessarily engage in practical action in relation to three orders of existence: the natural, the practical and the social. Practice in this sense is important, but I see it as leading to a focus on practice as action. Archer does not take this next step because she is anxious to avoid what she sees as the conflation of structure, agency and culture in practice theory. Whilst I concur with her concerns, I nevertheless suggest that, by returning to an early formulation in Roy Bhaskar's 
Transformational Model of Social Action (TMSA), we can avoid conflation by looking at the ways in which certain practices form logics of action which are at their most powerful when taken-for-granted.

Towards the end of this article, I consider questions of the taken-for-grantedness of practice, as well as the need to consider the material dimension of practices as instantiated in technological artefacts. However, to begin with, I explore the place of practices in Archer's and Porpora's morphogenetic framework (Porpora is an advocate Archer's work in this respect). Specifically, I discuss their approach to understanding certain contrasting religious practices. My analysis distinguishes between rituals and routines, and draws on insights from Weber and Foucault. To illustrate my argument, I consider the contrasting practices of religious communion in Scotland and England in the eighteenth century. These examples are used to illustrate the way in which analytical narratives of emergence, fostered by a morphogenetic approach, enable us to connect practices to their wider context.

\section{The place of practices in the morphogenetic framework}

Archer's morphogenetic framework encompasses practices. Nevertheless, I suggest that practices are underplayed because of a tendency to conflate 'practice' and 'practices'. Since 1995, Archer has published extensively on social theory informed by critical realism; the result is a complex, sophisticated and challenging body of work. Archer's original work provided the contextual conditions for the exercise of agency; more recently she has devoted attention to the nature of reflexivity, especially in formulating her views on the 'internal conversation' (Archer 2003). It is impossible to do justice to Archer's work in this short piece, so my focus here is on practice and practices in the context of her morphogenetic approach to structure and culture. Most of my analysis is based on her 1995 book Realist Social Theory, since this remains the work that most authors draw upon.

For the purpose of the present discussion, two aspects of Archer's treatment of cultural items - which she argues must be considered along with social items - are worthy of note. The first is that ideas about practices are not just limited to the performance of cultural practice but, once produced, can be incorporated into more enduring cultural items, such as theories, that then form the ideational context for subsequent rounds of performance. The second is that her discussion tends to involve large sweeps of time in which the focus is on grand ideas rather than more mundane practices. The same could be said for Realist Social Theory, in which Archer explicates her morphogenetic framework. Practices do not feature explicitly here, although it is important to note Archer's argument that the framework she proposes could be used at any scale of activity. As she puts it,

Analytical dualism can be used by any researcher to gain theoretical purchase on much smaller problems where the major difficulty of seeing the wood from the trees becomes much more tractable if they can be sorted out into the components of temporal cycles of morphogenesis - however short the time-span involved may be (Archer, 1996: 228).

She argues that the central dilemma of social theory, the relationship between structure and agency, has traditionally been addressed in three ways. Specifically, 'downwards conflationism' occurs when human activity is simply 'read off' structural conditions, as in forms of economic determinism; by contrast, 'upwards conflationism' involves the reduction of all social activity to individual action. Archer argued that when sociologists try to avoid these poles by refusing to grant primacy to either, they merely conflate the two, resulting in 'central conflationism'. She associated central conflationism with the structuration theory of 
Anthony Giddens (1976). Archer used her well-developed historical sociology to argue that the collapse of structure into action as 'memory traces' in Giddens' work prevented analysis of the interplay between the contexts in which actors found themselves involuntarily placed and the action that they engaged in. As Giddens drew extensively on practice theory, in which knowledge and skilled actors carried out the 'rules of the game' in producing and reproducing social life, it is perhaps not surprising that practice, as opposed to practices, came in for critique, identified as it was with forms of analysis that folded context into performance. However, it needs to be stressed that the morphogenetic approach is compatible with the assumption that social practices, and cultural ideas about such practices, are a key part of the structural domain.

A basic premise of the morphogenetic approach, as laid out in Figure 1, is that structural and cultural items have ontological status. Although these items are activity dependent, once they are produced they are relatively enduring. The method of analytical dualism allows researchers to examine the relationship between context and action over time. In Archer's words,

every morphogenetic cycle distinguishes three broad analytical phases consisting of (a) a given structure (a complex set of relations between parts), which conditions but does not determine (b), social interaction. Here, (b) also arises in part from action orientations unconditioned by social organization but emanating from current agents, and in turn leads to (c), structural elaboration or modification - that is, to a change in the relations between parts where morphogenesis rather than morphostasis ensued (Archer, 1995: 91).

Insert figure one about here

As I have argued, practices are not ruled out in a morphogenetic analysis but two factors, I would suggest, have rendered them relatively invisible in work which draws upon Archer. One is the broad sweep of the argument, which tends to deal with large scale societal change to make its points. The second is the lingering impact of the emergence of the ideas from the critique of practice theories, which tends perhaps to conflate practice and practices. It is to this conflation - and a clearer specification of the difference between practice and practices that I turn next.

\section{Practice and Practices}

The concern that practice theory, as exemplified by the work of Bourdieu (1990) and Giddens (1984), is guilty of 'central conflationism' stems from a focus on practice as action. In this view, the problem is that structure and culture are folded into activity. This activity is then seen as guided by habit, by largely unconscious dispositions that lead to the charge that persons are turned into 'zombies'. At best, they are cultural dopes who are 'performed' by the practices they engage in. The counter to this is to stress the capacity of persons to engage in reflection fuelled by their ultimate values. In order to do this, the emphasis is against notions of habit as guides to action. Porpora $(2015,153-5)$ for example, spends some time describing his own morning routine, stressing how it involves reflection at each stage. There are two problems with this. While it ably defends the notion of reflexive persons (and this is a stance to be held on to) it rather downplays the specification of practices by others. In the case of domestic routines, there is a strong degree of agential choice. However, Porpora citing Becker $(2015,127)$ has earlier endorsed an observation about rules, namely that: 'Differences in the ability to make rules and apply them to other people are essentially power differentials (either legal or extralegal). Those groups whose social position gives them weapons and power are best able to enforce their rules.' This is the situation which, as we will see, often 
obtains in formal organizations. It raises important questions about who makes the rules and who has the power to enforce them. That power is often, as Lukes (1974) would tell us, at its strongest when embedded in practices that are taken to be 'natural'. The second concern is the opening that the focus on creative performances gives to those who would focus on practices as patterns of behaviour. This has tended, in the organizational literature, to a focus on performance abstracted from the wider context which places limits on that performance (Mutch, 2016). The emphasis here is on change in a way that exaggerates the degrees of room for manoeuvre that are on offer.

A slightly different focus on practice is seen in Archer's formulations. Here practice is that which obtains as distinct from official formulations. That is, the focus is on what persons actually do, as opposed to what they are told to do or what they 'ought' to do. Thus, Archer contrasts what Roman Catholics do in relation to sexual practices (contraception, extramarital sex) with the official position on such practices. She then goes on to question the degree to which membership of the Catholic faithful depends on shared knowledge or understanding of those official positions. 'Every Sunday,' she observes, 'it is the duty of the faithful to say the Creed but, were it broken down into its component propositions, the most diverse array of understood meanings would result' (Donati and Archer 2015, 174). I argue the saying of the Creed is the practice, and it is the saying - rather than the understanding that is important. This becomes clearer when we take a comparative perspective. Creeds are a statement of official doctrines, boiled down from more abstruse theological debates. Other branches of Christianity also incorporate the recitation of such creeds into their liturgical practices, notably the Church of England in its Book of Common Prayer. In turn, this should be seen in the context of a wider practice, which is that of a specification for conducting services of worship. To be sure, such practices can be contested, but other Christian denominations reject both the recitation of creeds and tightly structured forms of worship. As opposed to creeds, those in the Reformed Protestant tradition have catechisms. The faithful are expected to understand these, and indeed, to recite them, but not as part of an act of worship. Rather, they are used for education and, in particular, as a test for worthiness to participate in an important practice that we will consider in more detail later, that of communion. ${ }^{2}$ The opposition to structured worship then becomes an article of faith in itself, a badge of commitment to a particular set of beliefs and practices, as with the Presbyterian commitment to extempore prayers. This is not to say that such denominations do not have forms of structure in their services but, for the present purpose, the contrast points up the importance of specified practices in Roman Catholic liturgical practice.

I will discuss the more conceptual aspects of this discussion further shortly, but first I want to illustrate the point with another historical example drawn from Presbyterian practice, specifically that found in Scotland. ${ }^{3}$ This is the practice of seated communion. Communion is a central practice in most Christian denominations. It involves the partaking of bread and wine, blessed by a religiously sanctioned individual, symbolic of the meal which Jesus was said to have presided over before his death and resurrection, the Last Supper. Disputes over the meaning and nature of the communion were a central issue in the European Reformation which saw Protestant denominations split from Roman Catholicism. The debates over whether the bread and wine were actually transformed into the blood and flesh of Christ (the transubstantiation thesis) or were merely symbolic are not our concern, although much real blood was spilled over such debates. However, such debates transformed practices of taking and receiving communion. As opposed to the individual kneeling and taking the communion elements from a priest, a practice grew up in Scottish Presbyterianism of taking communion in collective form. Seated at a table, the bread and wine, having been introduced to the table by the minister with injunctions from the Bible, were passed round from participant to 
participant (Torrance, 2014). This practice was justified by a reading of the Biblical texts in an effort to mirror the Last Supper, reflecting in turn a commitment to return to the practices of the primitive church as recorded in the Bible. Now, there are good reasons to doubt the theological warrant for this practice. In many ways, it could be read as developed in opposition to its Catholic 'other'. Nevertheless, it persisted, engendering a collective form of worship that some argue has influenced American revivalism (Schmidt 2001). That, in the eyes of some Presbyterian divines, was a cause for concern. Not only was obvious religious emotionalism rather frowned upon, but such practices, as memorably satirised in Robert Burns' 'The Holy Fair' provided opportunities for unruly gatherings prone to more secular forms of satisfaction. What this meant over time was the shift from sitting at a table to the reception of communion sat in pews in the body of the church, a practice which did not involve movement and so was considered to be more conducive of order and decorum. ${ }^{4}$ Nevertheless, the practice of remaining seated for this most important occasion in the church calendar became a taken-for-granted practice, one which only loses that status when contrasted to practices in other denominations.

Such contrasts are not just the province of the historian or the social theorist. Rather, they can be expressed by participants themselves under their own descriptions. A memorable example of this can be found in the contrast between the two cities, the Puritan Boston and the Quaker Philadelphia, essayed by Baltzell $(1979,367)$. In that discussion, which indicates the longterm impact of differential practices grounded in theological commitments, Baltzell (ibid, 367) reproduces the observation of a Unitarian to her Episcopalian friend: 'Eliza, do you kneel down in church and call yourself a miserable sinner? Neither I nor any member of my family will ever do that!' This suggests that posture at prayer, which can be kneeling, seated or standing depending on denomination, is a practice which conveys a sense of identity, regardless of the content of such prayers. As we have seen, and will develop, such practices cannot be seen as standalone items but as a set of interconnected practices which gain their meaning from relationships, both between the items, and in terms of an overarching social and cultural context. These examples should also indicate that, in order to surface such relationships, it is necessary to engage in comparative analysis, for it is only this which reveals their distinctive character (Steinmetz 1998). In the next section, I develop this discussion further by drawing a distinction between rituals and routines, one which I will then apply to religious practice in comparative fashion using historical examples drawn from eighteenth century Scotland and England. In this way, I hope to show that understanding the impacts of practices depends on our connection of them to their wider structural and cultural context.

\section{Weber, Foucault and Practices}

I start this discussion of the nature of practices with a revision of the nested set of concepts that Archer $(1996,1)$ uses for the structural dimension of social analysis: 'roles, organizations, institutions, systems'. My revision is to replace 'roles' with the suggestion that Bhaskar (1979) made in his initial formulation of the TMSA, 'position-practices'. Although a little clumsier than roles, it makes more visible the relationship of practices to particular 'slots' provided by broader structural arrangements. The focus then needs to be on the nature of such practices. Recognizing that there are a range of such practices, some of which may not be specified in advance and which are responses to the contingent exigencies of the particular position, the following discussion focuses on two which seem important: rituals and routines. Some dimensions of these, starting from and continuing with the religious contexts that we have already examined, are supplied by the work of Max Weber and Michel Foucault. 
At first blush, invoking Weber in the context of something as mundane as practices might seem surprising. After all, as Hennis (1988: 181) observes, 'in all social phenomena it is the non-everyday that interests him, that which bursts through everyday life'. We associate him with sweeping works of social analysis, most famously in the present context with his much misunderstood and contested work on 'the Protestant ethic' (Ghosh, 2014). Overlooked, however, in the ensuing debate are some hints about taken-for-granted practices in the essay on sects that was intended as an important complement to the original essay. In this Weber notes (in Gerth and Mills 1948, 312):

The tremendous social significance of admission to full enjoyment of the rights of the sectarian congregation, especially the privilege of being admitted to the Lord's Supper, worked among the sects in the direction of breeding that ascetist professional ethic which was adequate to modern capitalism during the period of its origin.

He went on to note, although only in passing, some organisational concomitants of this restriction of sacraments, such as the circulation of certificates amongst congregations. ${ }^{5}$ This presupposed, as we will see later, further organisational practices such as the recording of membership. It also required specific roles to maintain discipline and in this context the importance of lay elders (a term to be explained below) is stressed. This focus on the implication for practices of theological commitments has been pursued by Philip Gorski in his examination of the historical roots of the 'disciplinary revolution', in particular through a careful exploration of some of the organizational consequences of Reformed Protestantism in the Netherlands of the sixteenth century (Gorski 2003).

Such a focus usefully corrects the emphasis placed by those who follow Foucault on seventeenth- and eighteenth-century France. As Gorski comments, from Foucault's discussion 'one would expect a brief overview of the various disciplinary mechanisms invented by Protestant and Catholic religious reformers and of the ways in which territorial rulers utilized them as part of their strategies of domination'. However, as he further comments, 'On the concrete social mechanisms through which this power operated, the central concern of so much of his work, Foucault is strangely silent' (Gorski 2003, 24). It is not that Foucault does not both emphasize the need to examine such concrete mechanisms and that such mechanisms varied by denominational context. On the first point, Foucault $(2009,150)$ is clear that, while histories of beliefs and the organizations they spawned have been written, 'the history of the techniques employed, of the reflections on these pastoral techniques, of their development, application, and successive refinements, the history of the different types of analysis and knowledge linked to the exercise of pastoral power, has never really been undertaken.' This suggests the need to both uncover those specific techniques and to link them to those who had the power to shape them. Foucault proceeds to do this in some detail for one such technique, that of auricular confession (2009, 171-195). Using, it has it be said, a rather slim range of sources, Foucault examines the development of the practice during which an individual adherent confesses his $\operatorname{sins}^{6}$ to an individual priest through the mechanism of boxes designed for the purpose. ${ }^{7}$ This focus on a particular practice and its impact on the form of subjectivity characteristic of modernity, chiefly the internalisation of the discipline projected, has been the source of much later analysis by followers of Foucault. They, however, tend to neglect some of the gaps in his analysis, at times jumping straight from the discussion of eighteenth-century practices to those of the present day (Taylor 2009). Foucault himself was conscious that his analysis was restricted to one particular practice in one specific denomination. As he noted $(1999,177)$ at one point in his discussion in parentheses, 'I leave to one side the problems of Protestant countries; we will come back to 
them shortly from another angle'. In another place (Foucault 2009, 228) we find reference to aspects of the Protestant Reformation, 'whose history, what's more, it would be very interesting to trace'. However, these promissory notes were never cashed in, as he moved on to discuss other subjects, notably techniques of the self in classical Antiquity.

This, unfortunately, left a number of gaps in Foucault's analysis, although these in turn perhaps point to features which our analysis of practices has to pay attention to. One is that his emphasis on the confessional tends to divorce it from the range of practices in which it was entangled (Carrette 2000, 28). Another was his use of manuals for confessors as a guide to practice. The value of this is that it shows how practices may be linked to ultimate theological commitments through the specification in meso-level documents. However, without an examination of the practices themselves this can only ever be incomplete. This is not just because practices might evolve creatively as they are resisted or amended. It is also because it is often difficult to specify formally the full range of practices necessary to put prescribed rituals into practice. It is here that I want to introduce the distinction between rituals and the routines that are necessary to put them into operation. I accept some blurring in practice between these distinctions, but the distinction has value which I hope to demonstrate through concrete examples.

The cognitive psychologist Harvey Whitehouse $(2004,8)$ defines rituals as practices which display an excess over technical motivation and so invite exegesis. However, 'procedural competence is, therefore, somewhat disconnected from people's explicit concepts of why rituals take the form that they do'. As Asad $(1993,63)$ suggests, 'apt performance involves not symbols to be interpreted but abilities to be acquired according to rules that are sanctioned by those in authority: it presupposes no obscure meanings, but rather the formation of physical and linguistic skills'. That is, in many cases it is perfectly possible to take part in rituals successfully and give accounts of that performance, 'constrained more by commonsense principles than by the kind of complex theoretical knowledge available to experts' (Whitehouse 2004, 8). Hence the danger of seeking to construct ritual performances and their meanings from formal bodies of theology alone (Clark 2004, 125-142). Ritual is also important in making connections, connections that come from shared performance rather than, necessarily, shared values. So, observes Whitehouse, "what it means to be a regular churchgoer is not to be part of a particular group but to participate in a ritual scheme and belief structure that anonymous others also share' (Whitehouse 2004, 69). In turn, the rituals that are shared can become a powerful indicator of identity. Whitehouse observes that although, 'people who attend church regularly do not need to have quasi-theoretical knowledge of the links between standing and singing, kneeling and praying, and sitting and listening, such knowledge is bound to emerge over time' (Clark 2004, 125-142). That knowledge can then articulate particular identities which are shaped more by the common performance of the ritual than by more abstract theoretical considerations.

However, what is missing from this account are the practices which enable the rituals to take place in their particular form. These can be as basic as ensuring that the place where the ritual is performed is open and appropriately prepared. I call such practices 'routines'. I will illustrate the nature of such routines in the religious context shortly using the example of communion. However, thinking about what is needed to bring about the performance of rituals can lead us to a stream of work in organizational theory that seeks to characterize organizational routines. One aspect of this work has been the definition of routines as 'repetitive, recognizable patterns of interdependent actions, carried out by multiple actors' (Feldman and Pentland 2003, 95). Developed from a somewhat uncomfortable (and implausible) melange of Giddens and Latour, this has led to a focus on the performance of 
routines as a generative mechanism for organizational change. ${ }^{8}$ This tends to abstract routines from their wider organizational context, running the risk, as we have already noted, of obscuring the differential impact of those who set out the parameters for the exercise of routines. Far more helpful is the definition by Geoff Hodgson $(2008,21)$ in work influenced by dialogues with critical realism of organizational routines as 'organizational dispositions to energize conditional patterns of behaviour within an organized group of individuals, involving sequential responses to cues'. Hodgson's definition places the focus on organizational arrangements. The combination of a focus on organizational practices as rituals and routines has a number of implications for analysis. One is the need to place such practices in their structural and cultural context. From a structural perspective, we are interested in who has the power to specify the content of practices and who is licensed to participate in them. In what follows, differential rates of lay participation in certain religious practices are found to be of importance. From a cultural perspective, it is valuable to trace how pronouncements at an abstract conceptual level are translated into guidance for action. Here, absences, practices which are implied rather than being formally spelled out, are as important as what is formally promulgated. This combination of participation and guidance is revealed through an examination of situated action. Moreover, such action is best revealed by comparative analysis, comparisons which indicate what has been taken for granted. In turn, I will argue, such analysis points to the broader and enduring impact of the particular practices we have been examining. They form, that is, part of the structural and cultural conditioning of subsequent action, even when the beliefs that originally motivated them have, in relative terms, faded.

The example used to illustrate these points is the Christian ritual of communion as practiced in eighteenth-century Scotland and England. ${ }^{9}$ The key point of contrast here is between open and closed communion. In the former, there is no qualification for the receipt of communion, which is often taken frequently. The church aspires to be a universal one, only excluding from the ritual those who have been found guilty of breaking core tenets of the faith. The consequence is that only minimal routines are necessary to prepare the conditions for exercise of the ritual, such as purchase of the necessary materials. Such was the system that obtained in the Church of England, a Protestant religious polity characterised as Episcopalianism - that is, a form of hierarchical organization marked by the formal authority of the bishop. Matters are very different in closed communion. Here, the sacrament is restricted to those who have met entry qualifications, whether these be membership or knowledge. In the Reformed Protestant tradition represented by the Presbyterian Church of Scotland access to communion was restricted to those who could demonstrate their awareness of the basics of the belief system. In turn, this related to the emphasis placed on the understanding of the Biblical foundations that were held to be fundamental to faith. Accordingly, the catechisms that we met earlier were used as the basis for education and examination. Ministers held special sessions in which they expounded the catechism and they conducted annual examinations of the faithful to test their knowledge and hence their suitability for communion. This challenging and time-consuming task necessarily meant that communion was a rare event; it was generally only celebrated once a year in most parishes in the eighteenth century. A desire to streamline the process meant the introduction of rolls of those deemed fit to participate. Detailed examination was then limited to those, generally the young, who sought admission to communion for the first time. This, however, did not mean that the routine of examination faded, rather that it shifted to the scrutiny of rolls to make sure that all on it were in good standing. Over time, this evolved into the production of printed templates on which to enter the information, templates which also evolved in order to record attendance. At this point it is important to note who was doing this examination. In Presbyterianism, local parishes were 
administered by the minister together with a 'session' comprised of a number of 'elders'. Selected by the existing session and ordained for life (and so strictly speaking not 'lay') these elders assisted the minister in maintaining discipline in the parish, acting, as it were, as his eyes and ears amongst the congregation. It was this collective body which ran the routines which made the ritual of closed communion possible.

Once those who were fit to participate had been identified, some means of ensuring that they, and only they, had access to the communion venue was necessary. This was done by means of distributing metal tokens, generally of lead, bearing the year of communion and the parish name, to each communicant. Access to the communion venue was guarded by members of the session, who collected these tokens. They also served the tables, making sure that communion materials were present and order maintained. These duties could be onerous; as communion was only taken once a year it became a focus for mass participation, often involving significant numbers necessitating a series of consecutive sittings. After the event was over, sessions could count the communion tokens they had collected and so get a sense of how many had participated. Over time, the printed communion rolls became a means of recording this information, so that the participation of each individual in the congregation could be tracked. It should be clear that one concomitant of a belief in closed communion, which flowed from a particular interpretation of Biblical injunctions, was a range of routines which, in particular, demanded comprehensive record keeping.

One feature which characterised this branch of Christianity was a focus on the creation and dissemination of guides to local practice. A somewhat legalistic focus on the translation of Biblical tenets into everyday practice meant the creation of printed books of guidance. Starting in 1696, the Church of Scotland attempted to specify, in a manner redolent of contemporary organizational handbooks, how units of the church were to behave (Mutch, 2014). These efforts continued throughout the eighteenth century and established the standard for other important branches of the faith, notably in the United States of America. This translated a focus on order derived from Biblical injunctions into a more detailed set of prescriptions. ${ }^{10}$ However, this was never a complete guide to action, with many areas implicit rather than obvious. That is, examination of detailed practice reveals routines of accountability and record keeping that are clearly implied by injunctions about how rituals were to be conducted, but were nowhere spelled out. It is here that we need to bring in a further contrast with practice in England. Here, although a formally hierarchical system obtained, it was one which accorded considerable degrees of autonomy to local clerical incumbents. In turn, they were supported by limited lay participation. This was in the form of two churchwardens, who often served only annual terms of office. Thus, the whole system lacked the enduring, corporate form of Presbyterianism, meaning that consistent routines were difficult to establish. Guides for these officials appeared later than in Scotland and as the outcome of commercial calculation rather than official church policy. This meant that practice was a bewildering mixture of custom and tradition, often varying from area to area and bearing none of the appearance of a common system that characterised Scottish Presbyterianism.

This combination of rituals and routines had consequences beyond the boundaries of the religious, especially as in both cases the respective churches were the national churches. ${ }^{11}$ (The Church of England as the state church, established by law; the Church of Scotland as the de facto established church, even if this term is not strictly accurate). In order to see those consequences, we need to put the church systems in the context of supporting institutions, notably the law and education. The Scottish system rested on a degree of literate and numerate lay participation, capacities supplied by a basic education system which made 
Scotland the most literate country in Europe at the end of the eighteenth century. This strength in basic education was fostered by the ambition of the church to have a school in every parish to teach basic literacy. This was not in order to foster secular development (although it did that) but in order that the faithful could read their Bibles (and to provide a recruitment route for some of the most able into the ministry). In turn, the focus on laying down books of order in writing which attempted to work from first principles to lay down guidance for the performance of routines dovetailed nicely with a legal system which drew on Roman law traditions to privilege rules derived from first principles. The outcome of this was a very early production of a detailed set of 'Institutes of the Law of Scotland' in the midsixteenth century. This integrated set of institutions with shared or complementary practices which featured the specification of positions and practices with a focus on detailed record keeping and accountability contrasted sharply with the position in England.

In England, there was no attempt until the nineteenth century to create a national system of elementary education. As a consequence, educational provision was patchy and dependent on local initiatives. Furthermore, the English educational system was dominated by Oxford and Cambridge universities, which privileged the formation of character for the landed elite. This focus on character was in turn mirrored in the local administrative systems, which emerged from the hotchpotch of tradition and custom at local level. An emphasis on custom in England, resulted in the development of a body of law using common-law, and this system was established considerably later than the Scottish system. ${ }^{12}$ It is only by relating practices to their wider context, informed by a morphogenetic approach, that we can trace these broader consequences of taken-for-granted practices. This is an approach which accepts that performance is creative in response to changing conditions and engaged in by actors capable of reflection on their conduct and adjusting it accordingly, but suggests that the practices they encounter provide shaping conditions for that action, something to be pursued further in the next section.

\section{Practices and Morphogenesis}

Historical examples have been used to illustrate the value of viewing practices as a central part of the social world that persons encounter. They provide the immediate context within which action takes place, but mediate and mobilize wider structural and cultural logics. Focusing on practices, rather than practice, raises questions about how practices get to be the way they are and how they are perceived by those who engage in them. Alex Callinicos (1987, cf. Joseph, 2004) mobilizes Heidegger's notion of 'throwness' to explore how the most powerful practices are those which are taken-for-granted, which appear 'natural'. Persons enter into contexts which are already shaped by previous rounds of morphogenesis and, especially when practices seem to 'go with the grain' or are perceived as legitimate, can find it either easier or more appropriate to accept them. For Heidegger, this is the default state of 'being-in-the-world' and the constructed nature of practices only comes visible in situations of breakdown. While much 'routine' action involves, as Porpora suggests, often small adjustments to performance, such that each is, at one scale, unique, this might not disrupt the overall routine. Indeed, the most successful routines might be ones that enable precisely such degrees of flexibility without disturbing the overall purpose of the routine. However, while some change might come from resistance to the routine, it might also be engendered by changing states of the world beyond the routine, which call its effectiveness into question. The extent to which change is endogenous or exogenous is an empirical one, but one source of change might be the increasing situational logic of opportunity pointed to by Donati and Archer $(2015,325)$. This is because an increasing range of structural and cultural alternatives are on offer to persons, and their mobility between contexts could make 
them aware of these opportunities, causing them to question the routines they engage in. Thus, perhaps, in situations of morphogenesis, it is not only routine action that is called into question but routines themselves.

In investigating the nature of routines, historical investigation of religious practices suggests two important considerations: technology and mechanisms of diffusion. Behind the practices examined above lay changes in technology. For example, seemingly mundane matters such as changes in papermaking which made paper both more available and less expensive had an impact on the format of accounts in the eighteenth-century Church of Scotland, with cramped formats which sought to make the most of available space giving way to more expansive formats which used white space to make the provision of information clearer (Mutch 2012b). In some cases, however, these opportunities were not taken up, suggesting the ways in which taken-for-granted practices might endure long after new conditions of possibility would seemingly render them obsolete. In his study of the Reformation, Robert Wuthnow (1989, 149) has pointed to the way in which the new technology of printing was seized upon by Protestant reformers to distribute their ideas through the creation of new genre, the printed sermon. In this fashion, theological debates once reserved only for the religious elite became accessible to new social groups.

The historical examination of religious practices shows both the value of a morphogenetic approach, in that it helps us to connect practices to their wider cultural and structural context, and the value of incorporating practices into the morphogenetic framework. This does not challenge the overall framework for morphogenetic analysis, but supplies a nudge in the direction of examining the nature and formation of practices, as well as how they are performed. Whilst more might be said beyond my distinction between rituals and routines, nevertheless the distinction itself has proved extremely valuable in historical examinations of the conduct of religion, bringing to the fore aspects of social life that have been obscured by analyses that focus on institutions or beliefs. These remain vitally important in conditioning the practices with which actors must engage, but these practices cannot be simply 'read off' from formal statements of belief. The same approach might be valuable for examining other fields of activity in more contemporary settings. 


\section{Bibliography}

Archer, M. 1979. Social Origins of Educational Systems, London: Sage.

Archer, M. 1983. 'Process without System: Basil Bernstein and Pierre Bourdieu', Archives Européennes de Sociologie, 24, 196-221.

Archer, M. 1995. Realist Social Theory: The Morphogenetic Approach, Cambridge: Cambridge University Press.

Archer, M. 1996. Culture and Agency: The Place of Culture in Social Theory, Cambridge: Cambridge University Press.

Archer, M. 2003. Structure, Agency and the Internal Conversation, Cambridge: Cambridge University Press.

Archer, M. 2010. 'Can Reflexivity and Habitus Work in Tandem?', in Archer (ed) Conversations About Reflexivity, Abingdon: Routledge, 123-143.

Archer, M (ed). 2010. Conversations about Reflexivity, Abingdon: Routledge.

Asad, T. 1993. Genealogies of Religion: Discipline and Reasons of Power in Christianity and Islam, Baltimore: John Hopkins University Press.

Baltzell, E. 1979. Puritan Boston and Quaker Philadelphia: Two Protestant Ethics and the Spirit of Class Authority and Leadership, New York: Free Press.

Bhaskar, R. 1979. The Possibility of Naturalism, Hemel Hempstead: Harvester.

Bourdieu, P. The Logic of Practice, Cambridge: Polity.

Callinicos, A. 1987. Making History, Cambridge: Polity.

Carrette, J. 2000. Foucault and Religion: Spiritual Corporality and Political Spirituality, London: Routledge.

Clark, A. 2004. 'Testing the Two Modes Theory: Christian Practice in the Later Middle Ages', in Whitehouse, H. \& Martin, L. (eds) Theorizing Religions Past: Archaeology, History, and Cognition, Walnut Creek CA: AltaMira Press, 125-142.

Craig, C. 2011. The Scots' Crisis of Confidence, (second edition), Glendurael: Argyll Publishing.

Donati, P. and Archer, M., 2015. The Relational Subject, Cambridge: Cambridge University Press.

Feldman, M. and Pentland, B. 2003. 'Reconceptualizing Organizational Routines as a Source of Flexibility and Change', Administrative Science Quarterly, 48, 94-118.

Foucault, M. 2009. Security, Territory, Population: Lectures at the Collège de France 19771978, Basingstoke: Palgrave Macmillan.

Gerth, H and Mills, C., (eds)., 1948. From Max Weber: Essays in Sociology, London: Routledge \& Kegan Paul. 
Ghosh, P. 2014. Max Weber and The Protestant Ethic: Twin Histories, Oxford: Oxford University Press.

Giddens, A. 1976. New Rules of Sociological Method: a Positive Critique of Interpretative Sociologies, London: Hutchinson.

Giddens, A. 1984. The Constitution of Society, Cambridge: Polity.

Gorski, P. 2003. The Disciplinary Revolution: Calvinism and the Rise of the State in Early Modern Europe, Chicago: University of Chicago Press.

Hennis, W. 1988. Max Weber, Essays in Reconstruction, London: Allen \& Unwin.

Hodgson, G. 2008. 'The Concept of a Routine', in Becker, M. (ed) Handbook of

Organizational Routines, Cheltenham: Edward Elgar, 15-28.

Joseph, J. 2004. 'Being and Knowledge', in Archer, M. and Outhwaite, W. (eds) Defending Objectivity: Essays in Honour of Andrew Collier, Abingdon: Routledge.

Lukes, S. 1974. Power: A Radical View, London: Macmillan.

Mutch, A. 2003. 'Communities of Practice and Habitus: A Critique', Organization Studies, 24(3), 383-401.

Mutch, A. 2009. 'Weber and Church Governance: Religious Practice and Economic Activity', Sociological Review, 57(4), 586-607.

Mutch, A. 2011. 'Custom and Personal Accountability in Eighteenth Century South Nottinghamshire Church Governance', Midland History, 69-88,

Mutch, A. 2012a. 'Systemic Accountability and the Governance of the Kirk: The Presbytery of Garioch In the Eighteenth Century', Northern Scotland, 3, 45-65.

Mutch, A. 2012b 'Data Mining the Archives: The Emergence of Separate Books of Account in the Church of Scotland 1608-1800', Scottish Archives, 18, 78-94.

Mutch, A. 2013. “'Shared Protestantism' and British Identity: Contrasting Church Governance Practices in Eighteenth-Century Scotland and England', Social History, 38(4), 456-476.

Mutch, A. 2014. ' To Bring the Work to Greater Perfection': Systematising Governance in the Church of Scotland 1696-1800', Scottish Historical Review, 93(2), 240-261.

Mutch, A. 2015a. Religion and National Identity: Governing Scottish Presbyterianism in the Eighteenth Century, Edinburgh: Edinburgh University Press.

Mutch, A. 2015b. 'Pastoral Power and Governmentality: From Therapy to Self Help', Journal for the Theory of Social Behaviour, 268-285.

Mutch, A. 2016. 'Bringing History into the Study of Routines: Contextualizing Performance', Organization Studies, 37(8), 1171-1188.

Petterson, C. 2014. The Missionary, the Catechist and the Hunter: Foucault, Protestantism and Colonialism, Leiden: Brill. 
Popper, K., 1979. Objective Knowledge: An Evolutionary Approach, Oxford: Clarendon.

Porpora, D. 2015. Reconstructing Sociology: The Critical Realist Approach, Cambridge: Cambridge University Press.

Powell, W. and DiMaggio, P. (eds)., 1991. The New Institutionalism in Organizational Analysis, Chicago: University of Chicago.

Sayer, A. 2010. 'Reflexivity and the Habitus', in Archer (ed) Conversations About Reflexivity, Abingdon: Routledge, 108-122.

Schmidt, L. 2001. Holy Fairs: Scotland and the Making of American Revivalism, Grand Rapids, MI: Eerdmans Publishing Co.

Steinmetz, G., 1998. 'Critical Realism and Historical Sociology. A Review Article', Comparative Studies in Society and History, 40(1), 170-186.

Taylor, C. 2009. The Culture of Confession from Augustine to Foucault : A Genealogy of the 'Confessing Animal', New York: Routledge.

Torrance, I. 2014. 'A Particular Reformed Piety: John Knox and the Posture at Communion', Scottish Journal of Theology, 67(4), 400-413.

Whitehouse, H. 2004. Modes of Religiosity: A Cognitive Theory of Religious Transmission, Walnut Creek CA: AltaMira Press.

Wright, A. 2014. 'Organizational Routines as Embodied Performatives: A Communication as Constitutive of Organization Perspective', Organization, 23(2), 147-163.

Wuthnow, R. 1989. Communities of Discourse: Ideology and Social Structure in the Reformation, the Enlightenment, and European Socialism, Cambridge, MA: Harvard University Press.

\footnotetext{
${ }^{1}$ Strictly speaking, Archer's framework pays attention to not only change but also reproduction, and so the framework is sometimes referred to as the $\mathrm{M} / \mathrm{M}$ - morphogenetic/morphostatic - framework. For the sake of simplicity, I refer to the morphogenetic framework as a convenient shorthand.

${ }^{2}$ For an examination of Lutheran uses of the catechism to press particular worldviews in a colonial context, see Petterson, 2014.

${ }^{3}$ In order to avoid cluttering the text with footnotes, I will not refer to specific archival material, but the supporting evidence for what follows is to be found in Mutch 2011, 2012a and, especially, 2015a.

${ }^{4}$ Although not entirely; I observed communion being taken sat round white covered tables in the village hall in Lochranza, Arran, in 2016, including, on one table, the circulation of a common communion cup, the selfconscious revival of old practices designed to emphasise sociability.

${ }^{5}$ The implications of which are explored further in Mutch, 2009.

${ }^{6}$ What is confessed includes a range of thoughts and behaviours classified by the Roman Catholic church as sins.

${ }^{7}$ As explored in Mutch, 2015b

${ }^{8}$ For a pointed critique, even if one embedded in an otherwise contestable thesis, see Wright, 2014.

${ }^{9}$ Again, for an extensive discussion based on archival sources, Mutch 2015a.

10 'Let all things be done decently and in order': 1 Corinthians 14: 40

11 On this contrast, see Mutch, 2013.

${ }^{12}$ For an illuminating discussion of these contrasts in the context of contemporary Scotland, see Craig, 2011.
} 